\title{
Entrepreneurial leadership competencies among Malaysian university student entrepreneurial leaders
}

\begin{abstract}
Developments in entrepreneurial leadership as a distinct area of both research and practice raised many questions about the personal competencies of entrepreneurial leaders that enable them to successfully lead entrepreneurial endeavours. Although identifying entrepreneurs' specific capabilities has been one of the main focuses of entrepreneurship researchers, our knowledge is limited about personal leadership competencies required in entrepreneurial contexts. This qualitative study aimed to explore the personal competencies of undergraduate student entrepreneurial leaders in four Malaysian universities. Fourteen student entrepreneurial leaders were purposefully selected to participate in this study. Analysis of the semi-structure and in-depth interviews revealed different dimensions of proactiveness and innovativeness as previously identified competencies of entrepreneurial leaders for the student entrepreneurial leaders. Furthermore, love of challenges and versatility emerged as the personal competencies of the students. Implication of the findings and suggestions for developing entrepreneurial leadership competencies in university students through purposeful interventions are proposed.
\end{abstract}

Keyword: Entrepreneurship; Leadership; Entrepreneurial leadership competencies; University students; Malaysia 